kinetics in the newborn infant: Analysis by stable isotope technique. In: P. D. Klein and S. V. Peterson: Proceedings of the First International Conference on Stable Isotopes in Chemistry, Biology, and Medicine, p. 385, 1973. 22. Montreal, Quebec, Canada.

23. Boston, Mass

24. Stockholm. Sweden.

25. Beckman, Fullerton, Calif

26. We acknowledge the skillful technical assistance of Paulina Y. S. Yu and Susan B. Coffin and advice from Dr. Paul J. Thomas. The $\left[11,12-^{2} \mathrm{H}\right]$ chenodeoxycholic acid was generously provided by Merck, Sharp and Dohme, Ltd., Canada.

27. Dr. W. F. Balistreri is a Research Fellow, Children's Hospital Research
Foundation, University of Cincinnati, Ohio.

28. Dr. A. E. Cowen is an Eli Lilly Fellow. Present address: Department of Medicine Royal Brisbane Hospital, Australia.

29. The present address of Drs. P. A. Szczepanik and P. D. Klein is: Division of Biological and Medical Research, Argonne National Laboratory.

30. This research was supported in part by NIH Grant AM 16770 and grants-in-aid from the Mead Johnson Company, Eli Lilly and Company, and Weddel Pharmaceuticals (UK), as well as the Atomic Energy Commission.

31. Requests for reprints should be addressed to: A. F. Hofmann, M.D., Mayo Clinic, Rochester, Minn. 55901 (USA).

32. Accepted for publication June 3, 1975.
Corticotropin

fetus

glucocorticoids lung saline

\title{
Pulmonary Pressure-Volume Relationships after Corticotropin (ACTH) and Saline Injections in Fetal Rabbits
}

\author{
MARIE F. ROBERT, ANDREW T. BATOR, AND H. WILLIAM TAEUSCH, JR. (24) \\ McGill University-Montreal Children's Research Institute, and the Department of Physiologv, McGill University, \\ Montreal, Quebec, Canada
}

\section{Extract}

ACTH mixed with barium sulfate injected into fetal rabbits on day 24 of a 31-day gestation was associated with increased lung maturity compared with lungs of noninjected controls when assessed by deflation pressure-volume curves and lung weight to body weight ratios measured on day 27 . Fetuses injected with saline and barium sulfate also had accelerated (although somewhat less) lung maturation, perhaps from an $\mathrm{ACTH}$-mediated response to stress. The ACTH group $(A)$ maintained the largest lung volumes on deflation, followed by the saline group $(B)$, the ACTH controls $(C)$, and the saline controls $(D)$. Volumes (percentage of total lung capacity) between the two injected groups and their controls $(A$ versus $C ; B$ versus $D)$ were significantly different at transthoracic pressures of $15,10,7,4,0$, and $-2 \mathrm{~cm}$ water $(p<$ 0.05). Volumes (percentage of total lung capacity) between the ACTH group and the saline group $(A$ versus $B$ ) and between the two controls groups $(C$ versus $D)$ were not significantly different. Wet lung weight to body weight ratios were significantly different between the injected groups and their respective controls, between the two injected groups, and between the two control groups.

\section{Speculation}

Changes in pressure-volume relationships and lung weight to body weight ratios after injections of $\mathrm{ACTH}$ or saline into fetal rabbits support the hypothesis that fetal glucocorticoids are physiologic regulators of lung maturation.

In 1959, Avery and Mead (2) established that hyaline membrane disease is associated with inadequate amounts of surfactant in the premature lung. Pharmacologic means of inducing the fetal lung to produce surfactant precociously have been reported (17-19). In particular, glucocorticoids, in pharmacologic amounts, have been shown to accelerate lung maturation in various animal models ( 7 , 11 ), and have reduced the incidence of hyaline membrane disease in human infants treated prenatally (9). Sundell et al. (15) have found evidence of increased lung maturity and decreased hyaline membrane disease in lambs treated with continuous infusion of ACTH for 5 days before premature delivery. The aim of our study was to investigate further the effects of $\mathrm{ACTH}$ on lung maturation in fetal rabbits.

\section{MATERIALS AND METHODS}

Twenty-three white New Zealand rabbits were mated so that the onset of pregnancy was known to within $1 \mathrm{hr}(20)$. On dav 24 (I week before term), laparotomies were performed on pregnant does anesthetized with a halothane-oxygen mixture after intubation facilitated by exposure to ether. Three to five fetuses in each litter were injected intramuscularly (through the uterine wall), either with 0.25 or $1.00 \mathrm{mg}$ ACTH (21) mixed in saline with $15 \mathrm{mg}$ barium sulfate or with an equal volume $(0.1 \mathrm{ml})$ of saline and barium sulfate. These ACTH doses were chosen because they were found to be in excess of quantities sufficient to cause increases in peripheral blood levels of glucocorticoids in term newborn rabbits (16). Differences between fetuses treated with low or high doses of ACTH were not detected. Therefore, ACTH-injected fetuses are considered as a single group. Members of 10 litters received ACTH (and barium sulfate) with their noninjected littermates as controls; members of the other 13 litters received saline (and barium sulfate) with similar littermate controls. For purposes of comparison, the groups are labeled: group $A$, ACTH injected; group $B$, saline injected: group $C, \mathrm{ACTH}$ littermates; and group $D$, saline littermates. Experimental procedures were performed under sterile conditions. Barium sulfate, visible on radiograph, served as a marker to confirm that the injection entered the fetuses (4)

On day 27 ( $72 \mathrm{hr} \pm 8 \mathrm{hr}$ after injection), the does were killed 
with approximately $400 \mathrm{mg}$ pentobarbital intravenously. Viable fetuses were immediately removed within their amniotic sacs and killed with approximately $45 \mathrm{mg}$ pentobarbital. Each fetus was separated froms its placenta and sac, blotted dry, weighed, and a radiograph was taken.

The trachea of each fetus was cannulated and quasistatic pressure-volume measurements were made as in previous studies $(11,17)$. Total lung capacity was obtained at transthoracic pressures of $35-45 \mathrm{~cm}$ water. Subtotal deflation volumes were recorded as a percentage of total lung capacity to eliminate the effects of disparity in lung size.

The lungs of each fetus were then excised, blotted dry, and weighed. A portion of either right or left lower lobe was weighed and placed in an oven at $60^{\circ}$ for 1 week after which measurements of lung weight, being constant, were recorded as dry lung weight.

\section{RESULTS}

Figure 1 shows the deflation pressure-volume curves of the fetuses in four groups. Total lung capacity averaged $2.2 \mathrm{ml}( \pm 0.1$ $\mathrm{SEM})$ and did not vary significantly among the four groups. The ACTH group $(A)$ maintained the largest lung volumes on deflation, followed by the saline group $(B)$, the ACTH controls $(C)$, and the saline controls $(D)$. Volumes (percentage of total lung capacity) between the two injected groups and their controls $(A$ versus $C$; $B$

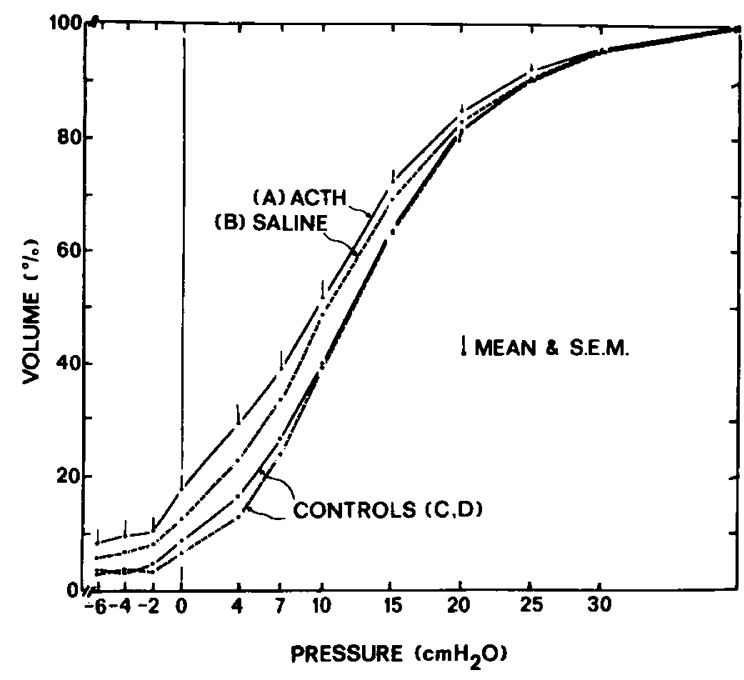

Fig. 1. Pressure-volume deflation curves of the injected fetuses and their noninjected littermate controls. The ACTH injected group $(A)$ maintained the largest lung volumes on deflation, followed by the saline injected group $(B)$, the ACTH controls $(C)$, and the saline controls $(D)$. The SEM for the ACTH curve is representative of the SEM calculated for the point of each curve at that pressure. versus $D$ ) were significantly different at transthoracic pressures of $15,10,7,4,0$, and $-2 \mathrm{~cm}$ water $(p<0.05)$. Volumes (percentage of total lung capacity) between the ACTH group and the saline group ( $A$ versus $B$ ) and between the two control groups ( $C$ versus $D$ ) were not significantly different.

Wet lung weight to body weight ratios (Table 1) were significantly different between the injected groups and their respective controls, between the two injected groups, and between the two control groups. Lung water as a percentage of lung weight did not vary significantly among the four groups, averaging $86.5 \%( \pm 0.4$ SEM).

\section{DISCUSSION}

Shifts in the relative position of the quasistatic deflation pressure-volume curve reflect alterations in either lung tissue elasticity or surface tension at the air-liquid interface of lung alveoli. The shift in the pressure-volume curve to the left after injections of ACTH or saline may have occurred because of alterations in the lung tissue causing decreased elasticity, because of increases in surfactant, or because of an interaction of these factors favoring increased compliance. Kotas and Avery (11) found that shifts to the left in the pressure-volume deflation curve with each day of gestation, or after glucocorticoid injection, were associated with decreased surface tension of lung extracts, suggestive of increased alveolar surfactant.

ACTH results in physiologic changes compatible with increased alveolar surfactant. Injected into the fetus, it may stimulate the adrenal glands to produce an endogenous rise in glucocorticoids adequate to accelerate lung maturation. Taeusch (16) has found no detectable rise in peripheral levels of glucocorticoids in response to exogenous ACTH injected into 27-day-old fetal rabbits. Others $(1,10)$ have indicated that adrenal vein glucocorticoid levels are many times greater than in peripheral blood, and Kittinger et al. (10) have shown increases in adrenal vein glucocorticoids in the near term fetal rhesus monkey in response to directly injected ACTH.

ACTH may also act directly at the lung. After incubation with ACTH, cyclic $3^{\prime}, 3^{\prime}$-adenosine monophosphate is increased in adult rat and fetal lamb lung cells (14). Stahlman et al. (13) have shown a rise in the number of lamellar bodies in type II lung cells after intraperitoneal injections of cyclic $3^{\prime}, 5^{\prime}$-adenosine monophosphate. Finally, a direct effect of ACTH on lung tissue elasticity cannot be ruled out. Seligsohn et al. (12) reported that ACTH injected into adult rabbits resulted in increased fibrinogen synthesis compared with saline-injected controls. It is possible that $\mathrm{ACTH}$, perhaps by altering protein metabolism in the lung, causes a change in tissue elasticity in addition to effects on surfactant. Whatever the mechanism, other investigators have implicated pituitary involvement in the regulation of lung maturation by demonstrating retarded lung development when the pituitary-adrenal axis is interrupted $(3,5,6)$.

Table 1. Measurements on fetal rabbits ${ }^{1}$

\begin{tabular}{|c|c|c|c|c|c|}
\hline Group & $n$ & $\begin{array}{l}\text { Wet lung weight, } \\
\text { g }\end{array}$ & Body weight, g & $\frac{\text { Wet lung weight }}{\text { Body weight }} \times 10^{3}$ & Water, $\%^{1}$ \\
\hline (A) ACTH injected & 26 & $0.630 \pm 0.025^{2}$ & $25.96 \pm 0.95$ & $24.4 \pm 0.6$ & $86 \pm 0.4$ \\
\hline (C) ACTH control & 25 & $0.675 \pm 0.025$ & $24.82 \pm 0.99$ & $27.3 \pm 0.6$ & $87 \pm 0.5$ \\
\hline$P^{3}$ & & N.S. ${ }^{4}$ & N.S. & $<0.01$ & N.S. \\
\hline (B) Saline injected & 32 & $0.640 \pm 0.026$ & $24.23 \pm 0.78$ & $26.3 \pm 0.5$ & $86 \pm 0.3$ \\
\hline (D) Saline control & 35 & $0.677 \pm 0.029$ & $22.87 \pm 0.70$ & $29.4+0.7$ & $87 \pm 0.5$ \\
\hline$P$ & & N.S. & N.S. & $<0.001$ & N.S. \\
\hline
\end{tabular}

$1100 \times \frac{\text { (Wet lung weight }- \text { dry lung weight) }}{\text { Wet lung weight }}$

2 SEM.

${ }^{3}$ Student $t$ test (two-tailed),

4 Not significant. 
Table 2. Comparison of fetal rabbits at 27 davs

\begin{tabular}{lc}
\hline \multicolumn{1}{c}{ Group } & Lung volume $^{1}$ \\
\hline Saline control & $39.5 \pm 2.5^{2}$ \\
ACTH control & $40.2 \pm 2.4$ \\
Saline injected & $48.0 \pm 2.3$ \\
ACTH injected & $5 ! .9 \pm 2.8$ \\
Glucocorticoid injected $^{3}$ & 76 \\
\hline
\end{tabular}

' On deflation as percentage of total lung capacity at a pressure of $10 \mathrm{~cm}$ of water.

${ }^{2}$ SEM.

${ }^{3}$ Reference 11.

Suprisingly, saline injections also affected pressure-volume relationships so that volumes between the ACTH group $(A)$ and the saline group $(B)$ were not significantly different. Alexander $e t$ al. (1) noted that after laparotomies and adrenal vein cannulations of fetal lambs there were insignificant fetal responses to exogenous ACTH. They suggested that the adrenal gland might fail to respond to exogenous $\mathrm{ACTH}$ if maximally stimulated by endogenous ACTH because of the stress of catheterization. In our experiment, the handling or the actual injection on day 24 might have stressed the injected fetuses enough to stimulate release of their own ACTH. It is unclear whether catecholamines released in response to stress on day 24 affect lung maturation. Wyszogrodski et al. (19) concluded that isoxsuprine, a catecholamine, may be associated with release of tissue stores of surfactant. In the fetal rabbit, isoxsuprine altered pressure-volume relationships when compared with saline-injected controls $3 \mathrm{hr}$ after injection on day 28 but not on day 26 or 27 when tissue stores of surfactant are presumably insignificant. Furthermore, in our study, it is possible that barium sulfate, given with each injection, contributed to the stress-induced physiologic changes in the lung by causing tissue inflammation at the injection site, although this was not obvious on gross inspection.

Lung weight to body weight ratios have been shown to be affected by glucocorticoids. Injected on day 24, glucocorticoids accelerate lung cell differentiation but inhibit lung cell proliferation in fetal rabbits, resulting in a decreased lung weight to body weight ratio (4). Evans et al. (8) noted that ACTH retarded somatic growth in normal adult rats but not in adrenalectomized rats. In our study (Table 1), lung weight to body weight ratios were significantly different between the two injected groups, between the injected groups and their controls, and between the two groups of controls. Lung water as a percentage of lung weight did not differ significantly among the four groups, supporting the interpretation that decreased lung weight to body weight ratios reflect decreased lung growth. The ACTH group had the smallest lung weight to body weight ratio, followed by the saline group, the ACTH controls, and the saline controls. Although lung weights and body weights are not significantly different between any of the groups, there is a puzzling tendency towards increased body weights with ACTH. After correction for uterine position and litter size, the order of relationships did not change and the lung weight to body weight ratios mentioned above remained significantly different.

In comparison with the glucocorticoid injections of Kotas and Avery (11), ACTH or saline has a lesser effect on lung maturity (Table 2). It is tempting to suppose a relative effect on the fetal lung of (l) pharmacologic amounts of glucocorticoids, (2) smaller amounts of glucocorticoids released in response to pharmacological ACTH, and (3) perhaps "physiologic" amounts of glucocorticoids, released in response to stress, probably mediated by endogenous ACTH.

\section{SUMMARY}

ACTH mixed with barium sulfate injected into fetal rabbits on day 24 of a 31 -day gestation was associated with increasee lung maturity compared with lung of noninjected controls when assessed by deflation pressure-volume curves and lung weight to body weight ratios measured on day 27 . Fetuses injected with saline and barium sulfate also had accelerated (although somewhat less) lung maturation perhaps from an ACTH-mediated response to stress.

\section{ADDENDUM}

After submission of our manuscript, a report has been published which indicates increased $\left[{ }^{14} \mathrm{C}\right]$ choline incorporation into lung phospholipid and decreased lung weight to body weight ratios after saline or cortisol injections in fetal rabbits, when compared with uninjected controls. These differences were not reflected in other, perhaps less sensitive, assays of surfactant synthesis. (Russell, B., Nugent, L., and Chernick, V.: Effects of steroids on the enzymatic pathways of lecithin production in fetal rabbits. Biol. Neonate 24 . 306-314 (1974)).

\section{REFERENCES AND NOTES}

1. Alexander, D., Britton, H., James, V., Nixon, D., Parker, R., Wintour, E., and Wright, R.:Steroid secretion by the adrenal gland of foetal and neonatal sheep. J. Endocrinol., 40: 1 (1968).

2. Avery, M., and Mead, J.: Surface properties in relation to atelectasis and hyaline membrane disease Amer. J. Dis. Child., 97: 517 (1959).

B B The role of the pitury-adrenal thyroid axes in lung differentiation. I. Studies of the cytology and physical properties of anencephalic fetal rat lung. Lab. Invest., 26: 306 (1972).

4. Carson, S., Taeusch, H., and Avery, M.: Inhibition of lung cell division afte hydrocortisone injection into fetal rabbits. J. Appl. Physiol., 34: 660 (1973).

5. Chiswick, M., Ahmed, A., Jack, P., and Milner, R.: Control of fetal lung development in the rabbit. Arch. Dis. Childhood, 48: 709 (1973).

6. deLemos, R.. Diserens, W., and Halki, J.: Delay in pulmonary maturation in goats resulting from fetal hypophysectomy. In: Combined Program and Abstracts, The American Pediatric Society, Inc., and the Society for Pediatric Research, p. 272 (Atlantic City, New Jersey, 1971).

7. deLemos, R., Shermeta, D., Knelson, J., Kotas, R., and Avery, M.: Acceleration of appearance of pulmonary surfactant in the fetal lamb by administration of corticosteroids. Amer. Rev. Resp. Dis., 102: 459 (1970).

8. Evans, H. Simpson, M., and Li, C.: Inhibiting effect of adrenocorticotropic hormone on the growth of male rats. Endocrinology, 33: 237.(1943).

9. Howie, R. and Liggins, G.: Prevention of respiratory distress syndrome in premature infants by antepartum glucocorticoid treatment. In: C. Villee, D. Villee, and J. Zuckerman: Respiratory Distress Syndrome, pp. $369-380$ (Academic Press, New York, 1973).

1C. Kittinger, G., Beamer, N., Hagemenas, F., Hill, J., Baughman, W., and Ochsner, A.: Evidence for autonomous pituitary-adrenal function in the nearterm fetal rhesus (Macaca mulatta). Endocrinology, 91: 1037 (1972).

11. Kotas, $R$, and Avery, $M$.: Accelerated appearance of pulmonary surfactant in the fetal rabbit. J. Appl. Physiol., 30: 358 (1971).

12. Seligsohn, U., Rapaport, S., and Kuefler, P.: Extra-adrenal effect of ACTH on fibrinogen synthesis. Amer. J. Physiol., 224: 1172 (1973).

13. Stahiman, M. Gray, M.. Lieu, S., and Chytil, F.: The role of cyclic AMP in lamellar body synthesis and secretion (Abstract.) Pediat. Res. 8: 470 (1974).

14. Stahlman, M., and Otten, A.: Personal communication.

5. Sundell, H., Tsiantos, A., Relier, J., Dolanski, E., Victorin, L., Otten, A., Strott, C., Orth, D., Chytil, F., and Stahlman, M.: Prevention of hyaline membrane disease with ACTH infusion in fetal lambs (Abstract.) Pediat. Res., 7: 407 (1973).

16. Taeusch, H.: Personal communication

7. Taeusch, H., Carson, S., Wang, N., and Avery, M.: Heroin induction of lung maturation and growth retardation in fetal rabbits. J. Pediat., 82: 869 (1973).

18. Wu, B., Kikkawa, Y., Orzalesi, M.. Motoyama, E., Kaibara, M., Zigas, C., and Cook, $C$ : The effect of thyroxine on the maturation of fetal rabbit lungs. Biol. Neonat., 22: 161 (1973).

19. Wyszogrodski, I., Taeusch, H., and Avery, M.: Isoxsuprine-induced alterations of pulmonary pressure-volume relationships in fetal rabbits. Amer. J. Obstet. Gynecol., 1/9: 1107 (1974)

20. Canadian Breeding Farm and Laboratories Ltd., St. Constant, Quebec.

21. Corticotrophin-carboxymethylcellulose, DURACTON, Nordic Biochemicals, Laval, Quebec.

22. The authors express deep appreciation to Drs. Mary Ellen Avery, Stephen H. Carson, and Isaac Wyszogrodski for their support and valuable suggestion and special thanks to Dr. Clement A. Smith for his review of the manuscript.

23. This research was supported in part by the Medical Research Council of Quebec.

24. Requests for reprints should be addressed to: H. W. Taeusch, Jr., M.D., Join Program in Neonatology, 221 Longwood Ave, Boston, Mass. 02115 (USA).

25. Accepted for publication June 3, 1975 